\title{
Imprint of the Rheasilvia impact on Vesta - Geologic mapping of quadrangles Gegania and Lucaria
}

\author{
Michael Schäfer ${ }^{\mathrm{a}, *}$, Andreas Nathues ${ }^{\mathrm{a}}$, David A. Williams ${ }^{\mathrm{b}}$, David W. Mittlefehldt ${ }^{\mathrm{c}}$, Lucille Le Corre ${ }^{\mathrm{d}}$, \\ Debra L. Buczkowski ${ }^{\mathrm{e}}$, Thomas Kneissl ${ }^{\mathrm{f}}$, Guneshwar S. Thangjam ${ }^{\mathrm{a}}$, Martin Hoffmann ${ }^{\mathrm{a}}$, \\ Nico Schmedemann ${ }^{\mathrm{f}}$, Tanja Schäfer ${ }^{\mathrm{a}}$, Jennifer E.C. Scully ${ }^{\mathrm{g}}$, Jian-Yang Li ${ }^{\mathrm{d}}$, Vishnu Reddy ${ }^{\mathrm{d}}$, \\ W. Brent Garry ${ }^{\mathrm{h}}$, Katrin Krohn ${ }^{\mathrm{i}}$, R. Aileen Yingst ${ }^{\mathrm{d}}$, Robert W. Gaskell ${ }^{\mathrm{d}}$, Christopher T. Russell ${ }^{\mathrm{g}}$ \\ ${ }^{a}$ Max Planck Institute for Solar System Research, 37077 Göttingen, Germany \\ ${ }^{\mathrm{b}}$ School of Earth and Space Exploration, Arizona State University, Tempe, AZ 85287, USA \\ ${ }^{\mathrm{c}}$ NASA Johnson Space Center, Houston, TX 77058, USA \\ d Planetary Science Institute, Tucson, AZ 85719, USA \\ e Applied Physics Laboratory, John Hopkins University, Laurel, MD 20723, USA \\ ${ }^{\mathrm{f}}$ Institute of Geological Sciences, Freie Universität Berlin, 12249 Berlin, Germany \\ $\mathrm{g}$ Institute of Geophysics and Planetary Physics, University of California, Los Angeles, CA 90095, USA \\ ${ }^{\mathrm{h}}$ NASA Goddard Space Flight Center, Greenbelt, MD 20771, USA \\ i German Aerospace Center (DLR), 12489 Berlin, Germany
}

\section{A R T I C L E I N F O}

\section{Article history:}

Received 4 March 2014

Revised 19 June 2014

Accepted 25 June 2014

Available online xxxx

\section{Keywords:}

Asteroid Vesta

Asteroids, surfaces

Geological processes

Impact processes

Tectonics

\begin{abstract}
A B S T R A C T
We produced two 1:250,000 scale geologic maps of the adjacent quadrangles Av-6 Gegania and Av-7 Lucaria, located in the equatorial region of (4) Vesta $\left(0-144^{\circ} \mathrm{E}, 22^{\circ} \mathrm{S}\right.$ to $\left.22^{\circ} \mathrm{N}\right)$. The mapping is based on clear and color filter images of the Framing Camera (FC) onboard the Dawn spacecraft, which has captured the entire illuminated surface of Vesta with high spatial resolution (up to $\sim 20 \mathrm{~m} / \mathrm{pixel}$ ), and on a digital terrain model derived from FC imagery. Besides the geologic mapping itself, a secondary purpose of this work is to investigate one of the most prominent morphological features on Vesta, namely the aggregation of several giant equatorial troughs termed the Divalia Fossae, most probably formed during the Rheasilvia impact near Vesta's south pole. The up to $465 \mathrm{~km}$ long and $22 \mathrm{~km}$ wide troughs show height differences of up to $5 \mathrm{~km}$ between adjacent troughs and ridges. Another imprint of the Rheasilvia impact is the $>350 \mathrm{~km}$ long and $\sim 250 \mathrm{~km}$ wide swath of ejecta crossing quadrangle Av-6 Gegania. This lobe shows a distinct appearance in FC color ratios and a high albedo in FC images, indicating a mineralogical similarity to material typically found within the Rheasilvia basin, in particular composed of diogenite-rich howardites. Almost the entire northern half of the mapping area shows the oldest surface, being dominated by upper crustal basaltic material. To the south, increasingly younger formations related to the Rheasilvia impact occur, either indicated by the troughs formed by Rheasilvia or by the Rheasilvia ejecta itself. Only medium sized impact craters with diameters less than $22 \mathrm{~km}$ occur within the two mapped quadrangles. Some of the craters exhibit ejecta blankets and/or distinctly dark or bright ejecta material in ejecta rays outside and exposures within the crater, and mass-wasting deposits down crater slopes, forming the youngest surfaces.
\end{abstract}

(c) 2014 Elsevier Inc. All rights reserved.

\section{Introduction}

NASA's Dawn spacecraft reached Asteroid (4) Vesta in July 2011 and started data acquisition using three different instruments. These are the Framing Camera (FC; Sierks et al., 2011), the Visible

* Corresponding author. Address: Max Planck Institute for Solar System Research, Justus-von-Liebig-Weg 3, 37077 Göttingen, Germany. Fax: +49551384979240.

E-mail address: schaeferm@mps.mpg.de (M. Schäfer). and Infrared Spectrometer (VIR; De Sanctis et al., 2011), and the Gamma Ray and Neutron Detector (GRaND; Prettyman et al., 2012). Dawn's mission at Vesta ended in September 2012. Several different scientific orbits at different altitudes were utilized (Russell and Raymond, 2011): the Survey orbit at $\sim 2750 \mathrm{~km}$ altitude, the High Altitude Mapping Orbit (HAMO) at $\sim 685 \mathrm{~km}$ altitude, the Low Altitude Mapping Orbit (LAMO) at $\sim 210 \mathrm{~km}$, and a subsequent continuation of the HAMO phase (termed HAMO2) at $\sim 685 \mathrm{~km}$ to image the initially shadowed north pole. 
As part of the geological analysis of the surface, the Dawn science team produced a global geologic map of Vesta, at a scale of 1:500,000 (Yingst et al., 2014) and a series of 15 quadrangle geologic maps at a scale of 1:250,000 (Fig. 1; cf. Williams et al., in press-a). While the global map (Yingst et al., 2014) was prepared by using HAMO data with a spatial image resolution of $\sim 60 \mathrm{~m} /$ pixel (i.e., the dimension of a single pixel on the ground near the equator is $\sim 60 \times 60 \mathrm{~m}^{2}$ ), the quadrangle mapping uses LAMO images with a resolution of up to $\sim 20 \mathrm{~m} /$ pixel.

In this work we present the geologic maps and analyses of the two quadrangles Av-6 Gegania (0-72 ${ }^{\circ} \mathrm{E}, 22^{\circ} \mathrm{S}$ to $\left.22^{\circ} \mathrm{N}\right)$ and $\mathrm{Av}-7$ Lucaria $\left(72-144^{\circ} \mathrm{E}, 22^{\circ} \mathrm{S}\right.$ to $\left.22^{\circ} \mathrm{N}\right)$. Fig. 1 shows the extent of both quadrangles, which are located in the equatorial region. All coordinates used in this paper are according to the 'Claudia' system introduced by the Dawn Science Team (Russell et al., 2012; Roatsch et al., 2012). At the time of this writing, the Planetary Data System (NASA) is providing Dawn data in a longitude system that can be obtained from the Claudia longitude by subtracting $150^{\circ}$. The topographic names used in this paper are approved by the International Astronomical Union (IAU) Working Group for Planetary System Nomenclature (WGPSN; http://planetarynames.wr.usgs.gov/; version as of February 2014).

\section{Data utilization and mapping methods}

\subsection{Framing Camera image products}

The Dawn FC acquired images using color filters in 7 bands between $\sim 0.4$ and $1.0 \mu \mathrm{m}$, and one panchromatic filter (termed clear filter). The FC color filter images exist in three standard levels from which we used level 1c data corrected for the 'in-field' stray light component (Kovacs et al., 2013), whereas the clear filter is practically unaffected and thus does not need any further correction beyond level 1b. We processed the PDS-formatted FC data using various applications of the Integrated Software for Imagers and Spectrometers (ISIS) suite version 3 (Anderson et al., 2004), which provides support for the conversion of Dawn FC data (Becker et al., 2012). Using ISIS applications, the corresponding color filter images are converted to I/F data, coregistered with each other, and photometrically corrected to standard viewing geometry using a Hapke model (Hapke, 2002). In order to improve the color image alignment, we first coregistered the image in one of the filters to a shape model (see Section 2.2); subsequently the remaining color images were coregistered to this base image. The images were then reprojected into an equirectangular map projection, and all clear filter images were combined into a mosaic of the entire vestan surface. We stacked the reprojected color filter images to create color cubes of all seven filters, and subsequently combined them into a global multi-band color mosaic of Vesta.

For the geologic mapping, we used two mosaics based on FC clear filter images; one is photometrically corrected (not shown here), and one is uncorrected (Fig. 2A). We filled gaps in the LAMO mosaic due to incomplete image acquisition using HAMO data. This final mosaic was used as an underlying map for the geologic mapping. Fig. 2B shows a subset of a photometrically corrected $0.55 \mu \mathrm{m}$ filter mosaic from HAMO and HAMO2 phases corresponding to the mapping area of both quadrangles.

We created diverse false color composite maps using FC color filter data. We primarily used a combination of color ratios introduced for the Clementine mission (Pieters et al., 1994), which has been applied on FC data (Reddy et al., 2012a). In the following, this color composite is called 'Clementine color ratios' (see Fig. 2C) and consists of a RGB display using the reflectance ratios 0.75 / $0.44 \mu \mathrm{m}$ as red, $0.75 / 0.92 \mu \mathrm{m}$ as green, and $0.44 / 0.75 \mu \mathrm{m}$ as blue. The resulting red and blue colors indicate the visible spectral slope, whereas the greenish colors are a proxy for the depth of the $1-\mu \mathrm{m}$ absorption band caused mainly by the presence of FeO-bearing pyroxene.

\subsection{Shape model data}

We used a digital terrain model (DTM) for the investigation of Vesta's topography. The DTM is based on the shape model of Vesta derived from FC clear filter images and features 96 pixels per degree, i.e., a pixel near the equator has a spatial dimension of $\sim 45 \times 45 \mathrm{~m}^{2}$ (Gaskell, 2012; version as of 2013/05/22). Using the DTM, we calculated height values referred to an ellipsoid of the dimensions $a=b=285 \mathrm{~km}$ and $c=229 \mathrm{~km}$. Fig. 3A shows this ellipsoid-based DTM in a color-coded display. We used the DTM also to obtain slope maps (Fig. 3B) and artificial shaded relief maps displaying different illumination conditions (Fig. 3C), as well as cross sections. These three maps were combined together using semitransparent overlays to produce topographic maps (see Section 4 for examples). Additionally, we used the shape model to display FC images in perspective views, and during FC image processing for both georeferencing and photometric correction of the FC images.

\subsection{Mapping approach and tools}

The color and clear filter FC image mosaics, and the DTM data were imported in the software ArcGIS by ESRI as a basis for our
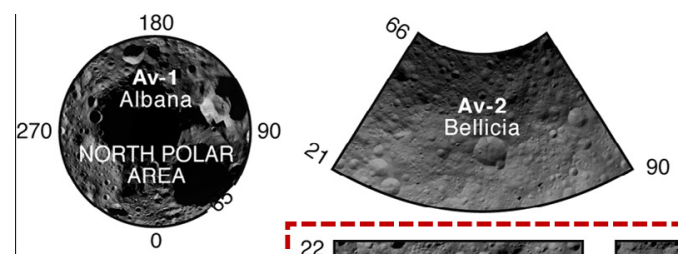

90

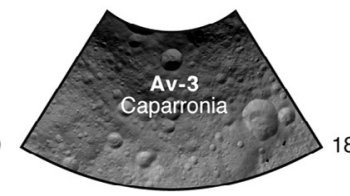

180
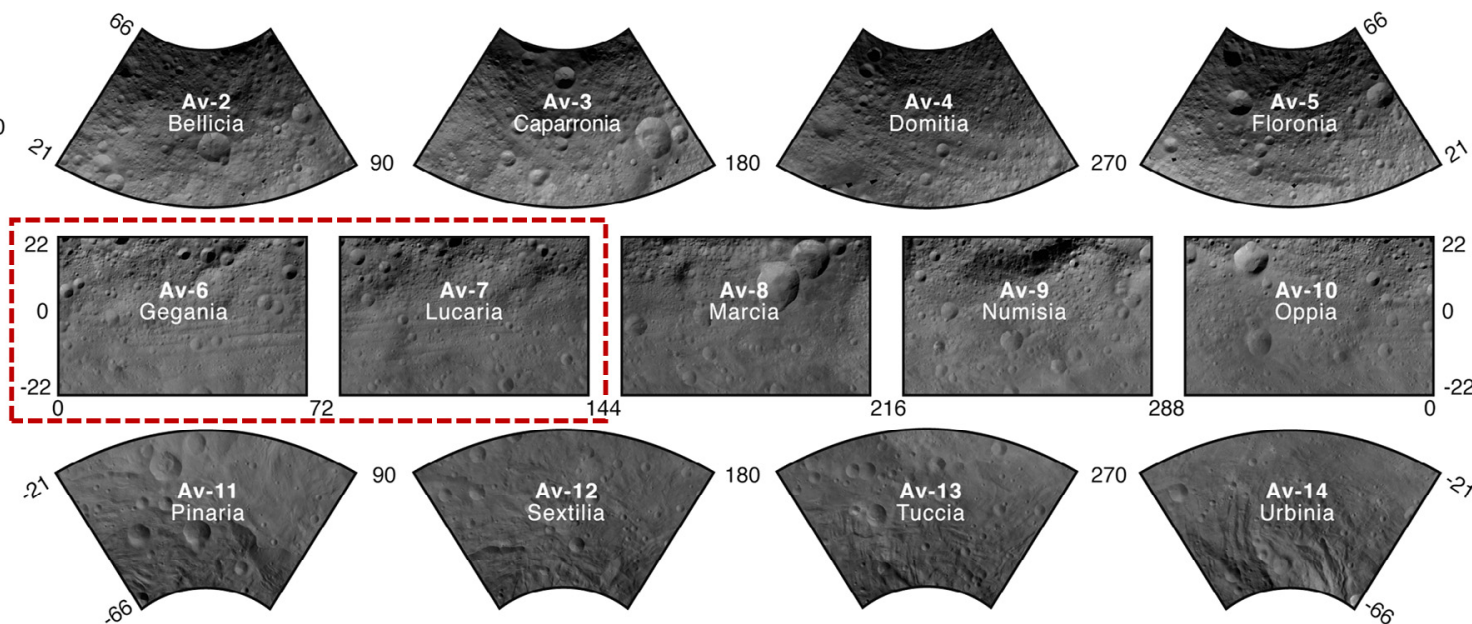

90

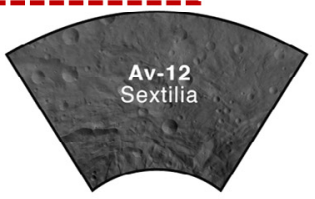

180
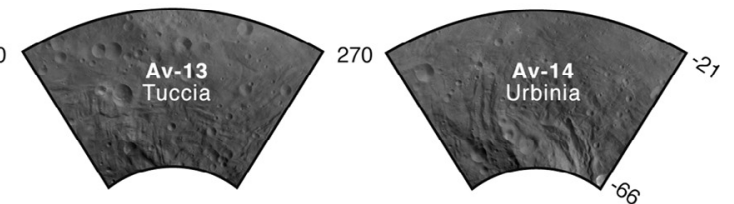

Fig. 1. Definition of mapping quadrangle tiles on (4) Vesta highlighting the two quadrangles Av-6 Gegania and Av-7 Lucaria mapped in this paper. 


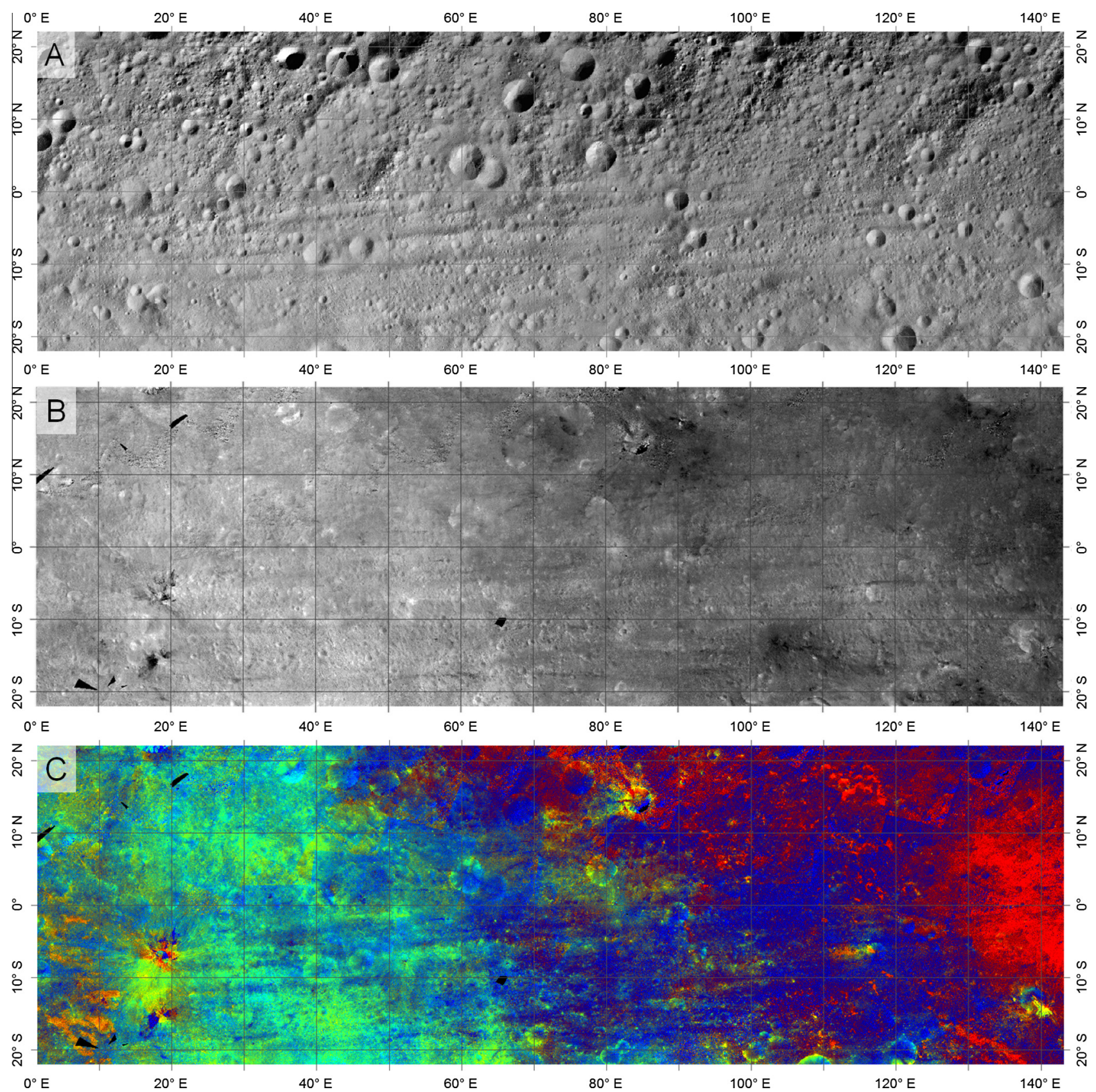

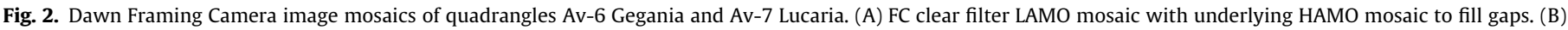

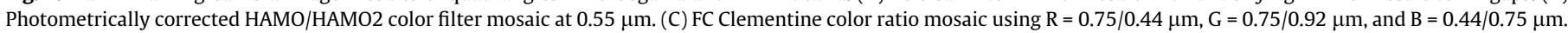
(For interpretation of the references to colour in this figure legend, the reader is referred to the web version of this article.)

geologic mapping. We used the clear filter image mosaic for the identification of units and their appearance, regarding, e.g., albedo, morphology, and texture. For the investigation of albedo variations, e.g. of bright and dark materials, we used the photometrically corrected clear filter mosaic.

The spectral information within the FC color cube mosaic is used to compositionally distinguish the geologic units. From this cube, we extracted color spectra and created false color composite maps, i.e., the Clementine color ratios described in Section 2.1. We performed spectral data analyses of the color filter cube using the software ENVI by Exelis VIS.

In addition, we investigated the topography and morphologic surface features using the shape model of Gaskell (2012). For these DTM analyses we also utilized the software ENVI, e.g., creating topographic cross sections and image visualizations in 3D.
Contacts of map units crossing the quadrangle boundaries were cross-checked with the maps of neighboring quadrangles. For further information on the mapping process see Williams et al. (in press-a).

\section{Results}

\subsection{Geologic setting}

The global mapping of Vesta resulted in the definition of four distinct terrains (Yingst et al., 2014). First, the south polar and southern latitude region contains the relatively lightly-cratered floors of the Rheasilvia and Veneneia basins (termed Rheasilvia Formation). This terrain includes three subunits Ridged and grooved terrain, Smooth terrain, and the Central peak area of the Rheasilvia basin. Secondly, the equatorial, highly-cratered terrain 


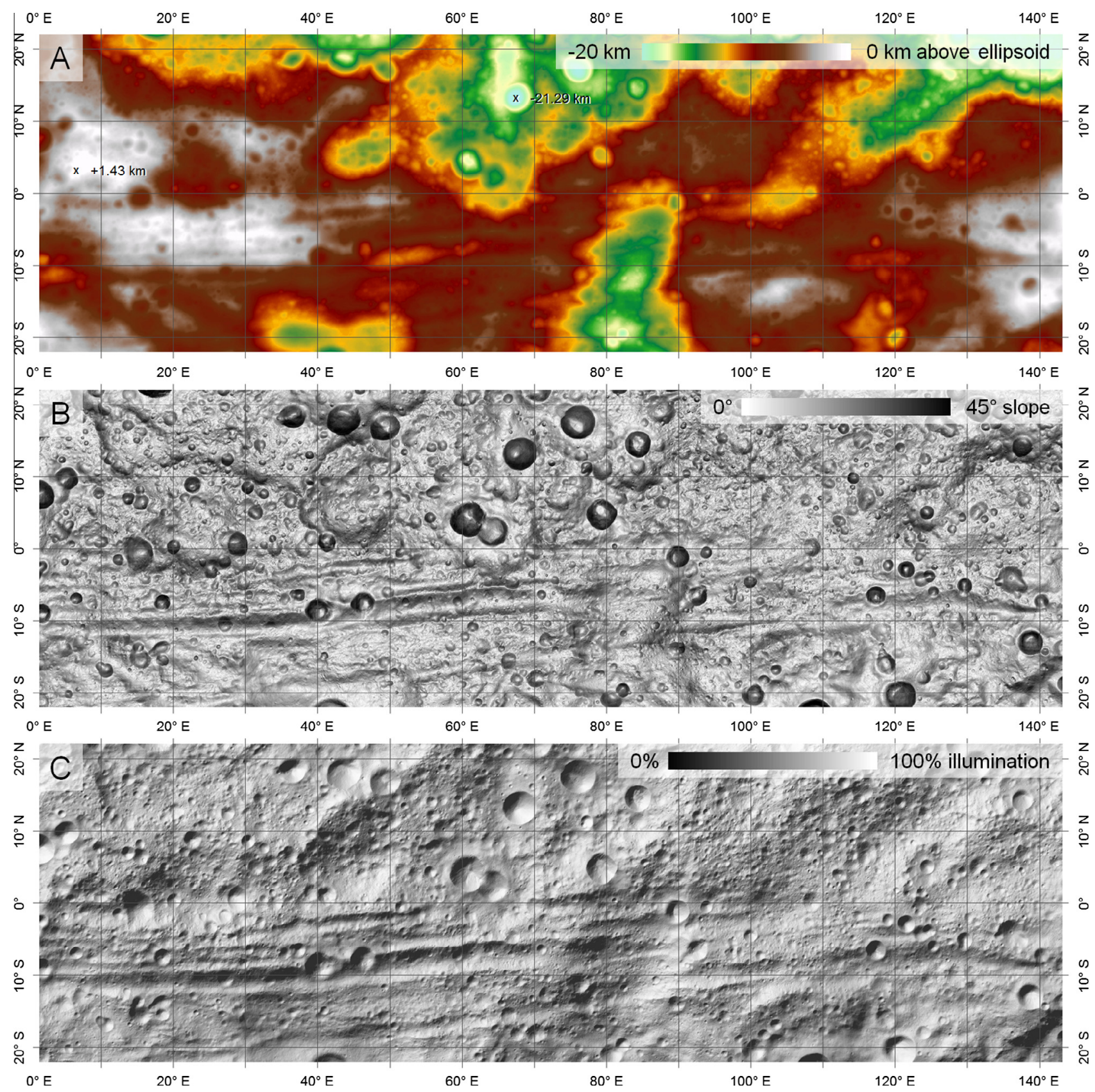

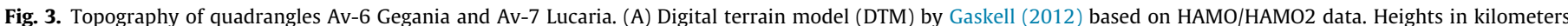

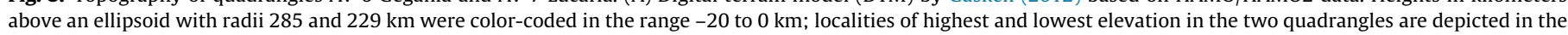

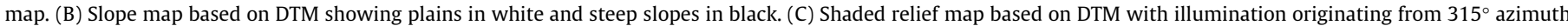
and $45^{\circ}$ altitude angle. (For interpretation of the references to colour in this figure legend, the reader is referred to the web version of this article.)

that contains the set of ridges and troughs formed in response to the Rheasilvia impact event (Buczkowski et al., 2012) is named the Divalia Fossae Formation. Third, the equatorial, highly-cratered topographic highland termed Vestalia Terra, which interrupts the Divalia Fossae troughs. Last, the north polar and northern latitude region is a heavily-cratered terrain which has been mapped either as cratered highlands or, where it contains the Saturnalia Fossae ridges and troughs, as Saturnalia Fossae Formation.

The mineralogical vestan surface composition can spectrally be linked with the HED meteorite class (Howardite-Eucrite-Diogenite) found on Earth (Keil, 2002, and references therein). The HED meteorites are comprised of pyroxene-plagioclase basalts (eucrites) as likely vestan upper crustal material, igneous orthopy- roxenites (diogenites) assumed to originate from the lower vestan crust, and impact breccia (howardites) composed of eucritic and diogenitic fragments (Keil, 2002). These mineralogical differences have spectrally been investigated on Vesta using both VIR data (De Sanctis et al., 2012), and FC data (Thangjam et al., 2013), showing an overall howarditic mineralogy, with regions of increased diogenitic appearance (mainly within and in the vicinity of the Rheasilvia basin), and areas of more eucritic howardites (mainly along the vestan equator).

We define our map units and structural features based on those introduced for the global geologic map of Vesta (Yingst et al., 2014), except for some updates required to account for specific features in our quadrangles. Fig. 4 shows the combined geologic map 


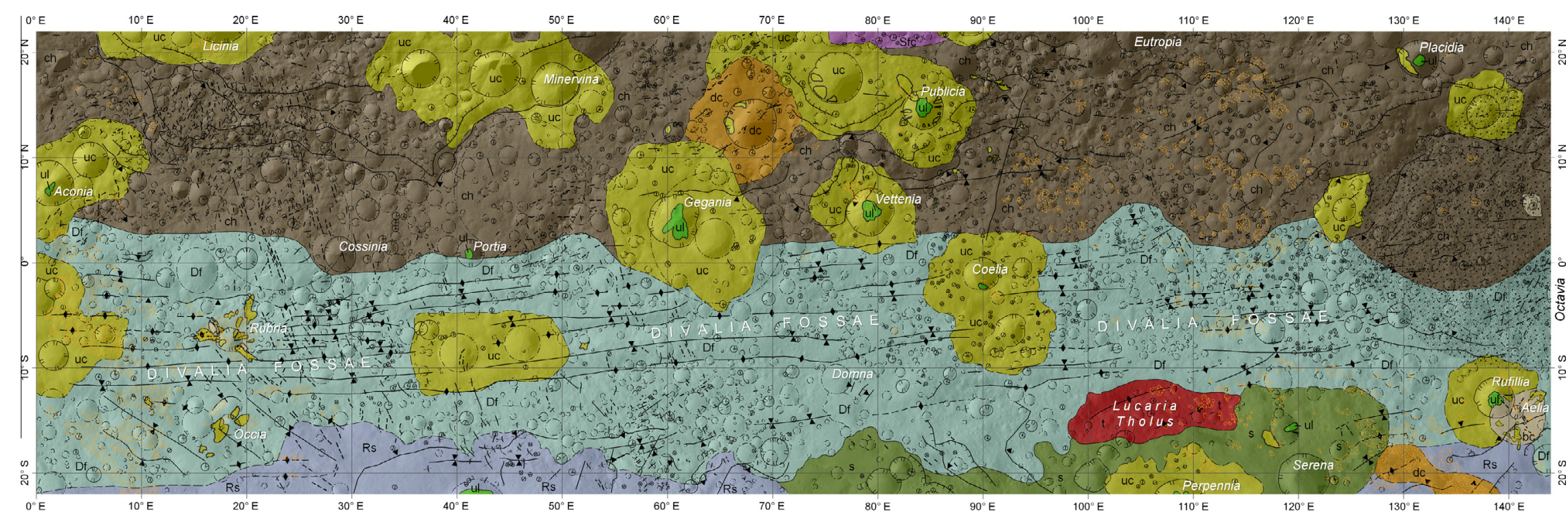

\section{Legend}

\section{Mass wasting deposits}

ul Undifferentiated lobate material

Crater materials

uc Undifferentiated crater material

bc Bright crater material

dc Dark crater material

bcr Bright crater ray materia

dcr Dark crater ray material

Surficial deposits

Lobate "orange" material

Q.5. Dark diffuse mante materia

\begin{tabular}{|c|c|}
\hline Rheas & Ivia Formation \\
\hline$s$ & Smooth material \\
\hline Rs & Rheasilvia smooth terrain \\
\hline Df & Divalia Fossae Formation \\
\hline Saturn & alia Fossae Formation \\
\hline $\mathrm{Sic}$ & Saturnalia Fossae cratered terrain \\
\hline Pr & Ieneian Period \\
\hline & Tholus material \\
\hline & Cratered highlands material \\
\hline
\end{tabular}

Linear features and crater rims

It Trough

$\rightarrow$ Ridge crest, certain $\quad+1$ Groove

- +- Ridge crest, approximate $\quad \pi \|$ Crest of crater rim

T Scarp crest $\quad$-...-.. Crest of buried crater rim

111 Scarp base

+ Depression margin

Unit contacts

- Certain contact

--- Approximate contact

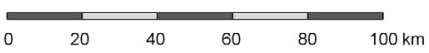

Fig. 4. Geologic map of quadrangles Av-6 Gegania and Av-7 Lucaria based on Dawn FC LAMO imagery ( $20 \mathrm{~m} /$ pixel spatial resolution). Map legend includes a correlation of map units (COMU) for both quadrangles, showing relative stratigraphic relationships between map units (note that time axis is not to scale). Two separate high resolution maps for each quadrangle can be found in the supplementary online material. 

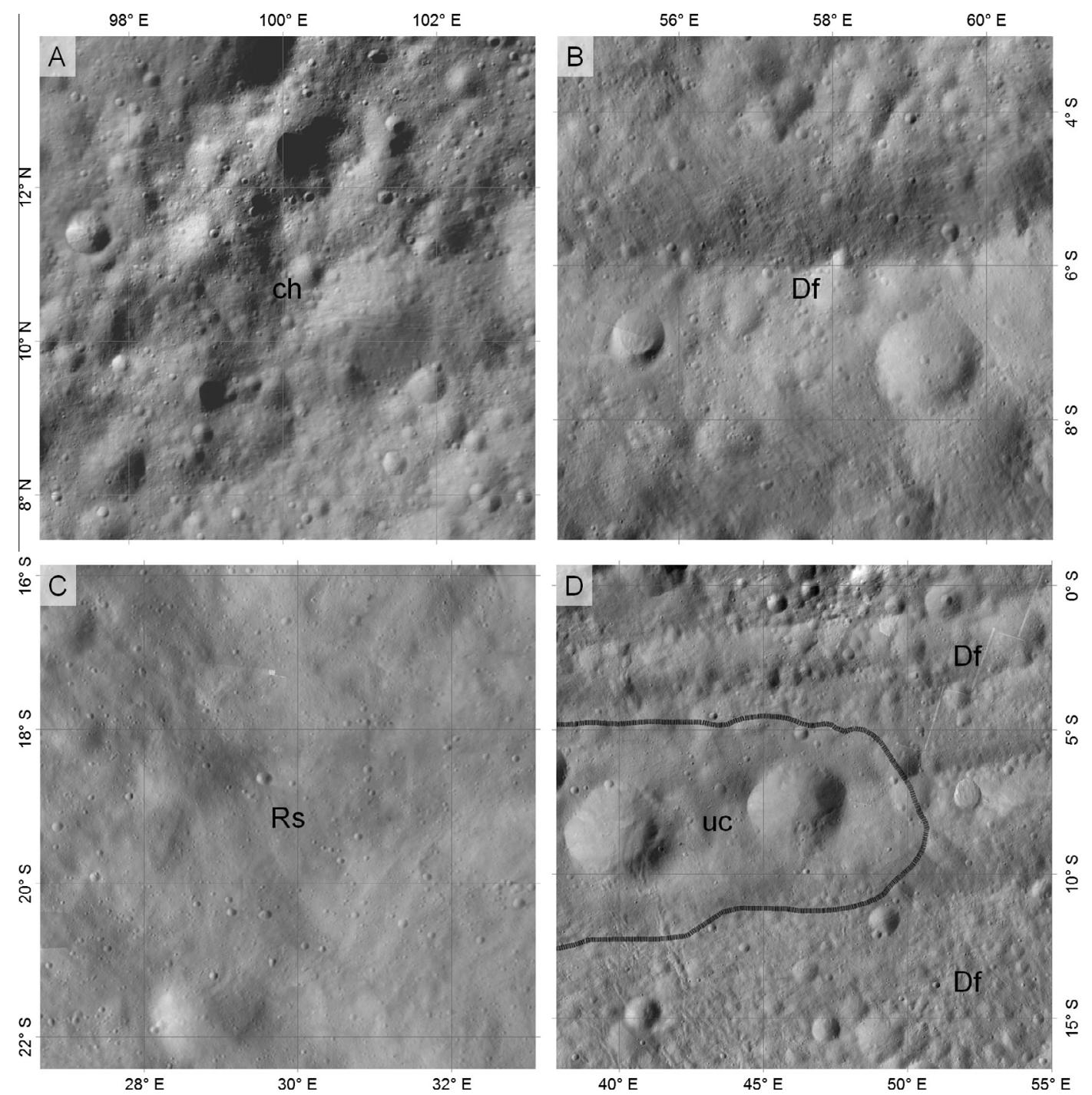

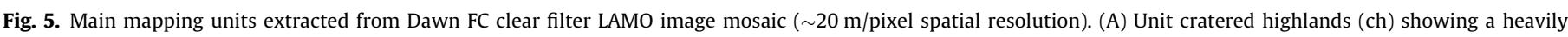

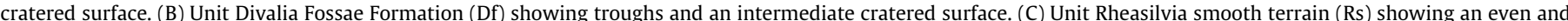

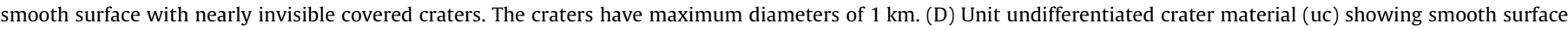
texture by impact ejecta, which even smoothed the troughs of unit Df. Note that figure D shows a different map scale than figures A-C.

of quadrangles Av-6 Gegania and Av-7 Lucaria. The mapped quadrangles are located in the equatorial region of Vesta (Fig. 1) and feature mainly three units that show differences in texture, crater density, and topography: the Cratered highlands material (ch), the Divalia Fossae Formation (Df), and the Rheasilvia Formation (units Rs and s). These main units are separated by scarps, which are probably ancient crater rims or troughs. The northern portions of both quadrangles are mapped as the unit ch, a heavily cratered terrain that shows subjectively the highest crater counts in the mapping area and thus is likely the oldest surface relatively to the other units. Unit ch is continued to the north in quadrangles Av-2 Bellicia (Ruesch et al., 2014) and Av-3 Caparronia (Scully et al., 2014; Ruesch et al., 2014). To the south, ch borders unit Df at approximately $0-5^{\circ} \mathrm{N}$, and continues to the east into quadrangle Av-8 Marcia (see Williams et al., in press-b) and to the west into quadrangle Av-10 Oppia (see Garry et al., this issue). The unit Df comprises the large, flat-floored, east-west-striking equatorial troughs that are separated by prominent ridges. Df dominates the southern area of both quadrangles. The troughs occur in the highest terrains of the quadrangles, relative to the ellipsoid. The surface is strongly cratered including some medium-sized craters (diameters $10-25 \mathrm{~km}$ ), which are superimposed on the troughs and partly obliterate them. In the south of the mapping area, the Rheasilvia Formation (unit Rheasilvia smooth terrain; Rs) and a further undivided unit Smooth material (s) adjoin unit Df. These units are more prominent in the two geologic maps to the south, the Av-11 Pinaria and Av-12 Sextilia quadrangles (for a description see Krohn et al., in press). These units have a smooth morphology containing very few craters, indicating the gradual transition to the ridged and grooved terrain of the southern hemisphere. On the northern border of quadrangle Av-7 Lucaria we mapped a small area of Saturnalia Fossae cratered terrain (Sfc) in order to coincide with the map of quadrangle Av-2 Bellicia (Ruesch et al., 2014).

\subsection{Description, interpretation and discussion of map units}

In the following subsections, we give detailed descriptions of the map units (DOMU) used in the mapping, followed by their interpretation and, where appropriate, by a discussion. The correlation of map units (COMU) in the lower right part of the geologic map (Fig. 4) depicts the relative stratigraphic relationships between the map units. Fig. 5 illustrates four examples of FC images for the main material units occurring in the mapping area. 

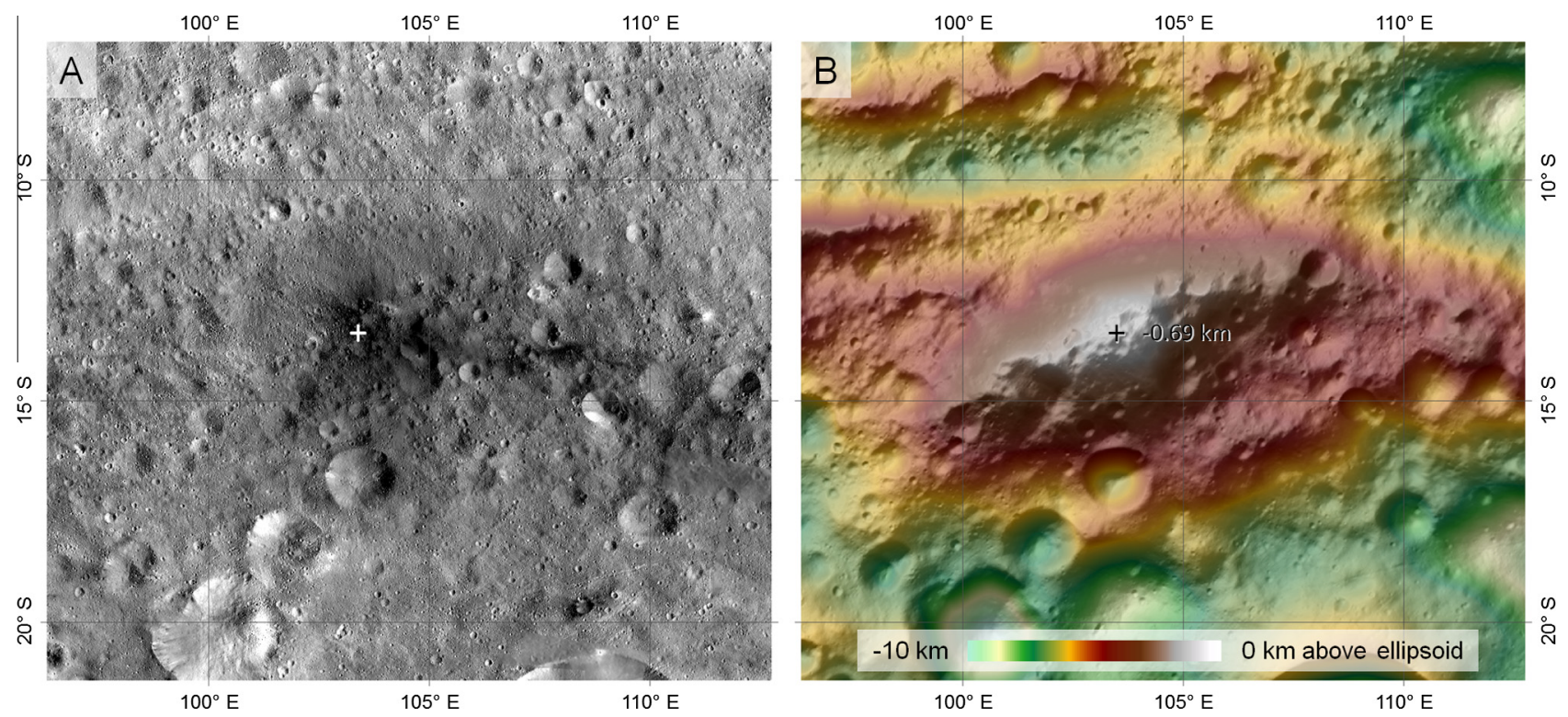

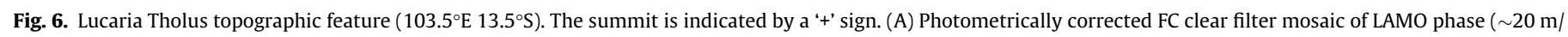

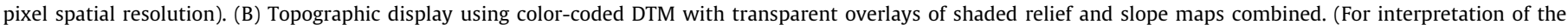
references to colour in this figure legend, the reader is referred to the web version of this article.)

\subsubsection{Pre-Veneneian period: cratered highlands material (ch)}

Description: Almost the whole northern area of Vesta is built up of unit ch, that occurs in the mapped quadrangles north of approximately $0-5^{\circ} \mathrm{N}$ latitude. Unit ch is a highly cratered surface (Fig. 5A) and shows the highest crater densities found on Vesta, while lacking large-scale tectonic features (Ruesch et al., 2014). The ch unit shows a medium albedo in FC clear filter mosaics and purple to bluish colors in Clementine color ratios.

Interpretation: Unit ch is interpreted as upper crustal material dominated by eucritic howardites and likely represents the oldest surface on Vesta, predating the Veneneia impact.

\subsubsection{Pre-Veneneian period: Tholus material $(t)$}

Description: The unit t occurs only at Lucaria Tholus within in Av-7 $\left(103.5^{\circ} \mathrm{E} 13.5^{\circ} \mathrm{S}\right)$. Lucaria Tholus is an unusual hill that is the namesake of quadrangle Av-7. Fig. 6 shows the approximately $40 \mathrm{~km}$ long topographic high containing a ridge crest, which has a slightly different orientation than the nearby E-W-striking equatorial troughs of the Divalia Fossae Formation. Dark material can be seen in the form of long lobate deposits caused by downslope movements to the east (Reddy et al., 2012b). The low-albedo material appears to originate from a crater at the top of the hill, which also shows the darkest surface. In Clementine color ratio images the Tholus material appears as dark purple colors.

Interpretation: Dark material of likely exogenous origin that is superposed on a topographic high between the ridges of the Divalia Fossae. In contrast, according to Yingst et al. (2014) Lucaria Tholus is a remnant of a volcanic feature (dike, intrusion, or volcanic cone), which has been exposed by impacts.

Discussion: The co-occurrence of a topographic high and low albedo material is likely coincidental, and may not be related with a volcanic feature. In our opinion, the low albedo material more likely originates from a CM2 type impactor, as suggested by Nathues et al. (2014).

\subsubsection{Saturnalia Fossae Formation: Saturnalia Fossae trough terrain (Sft) and Saturnalia Fossae cratered terrain (Sfc)}

Description: The Saturnalia Fossae Formation consists of two subunits: Sft containing the Saturnalia Fossae troughs (not occurring in the mapping area) and Sfc containing a differing set of troughs, which are more subdued, less abundant and show differing fault planes (Ruesch et al., 2014). Unit Sfc shows very similar appearance as unit ch, i.e., comparable albedo and crater density. In contrast to ch, Sfc and Sft show both large-scale troughs and ridges and more pronounced small-scale lineations like grooves, pit crater chains and ridges (Ruesch et al., 2014). The sub-unit Sfc covers only a minor area in the very north of quadrangle Lucaria $\left(270 \mathrm{~km}^{2}\right.$, resp. $0.2 \%$ of the mapping area).

Interpretation: Sfc is interpreted as vestan upper crustal material (similar to ch).

Discussion: Unit Sfc has mainly been mapped for alignment with the quadrangle Av-2 Bellicia in the north, mapped by Ruesch et al. (2014), who give a detailed description. According to Ruesch et al. (2014), Sfc can be interpreted as ancient vestan crustal material, which has been tectonically deformed by several large unknown impacts, unlike the Saturnalia Fossae troughs of unit Sft, which can be related to the Veneneia impact event.

\subsubsection{Rheasilvia Formation: Divalia Fossae Formation (Df)}

Description: Unit Df is located in the southern half of the two mapped quadrangles. The terrain is dominated by several ridges and flat-floored troughs trending more or less parallel to the vestan equator (see Section 3.3 for a detailed description of the troughs). The surface of unit Df is strongly cratered by impacts (see Fig. 5B and D), including 22 craters of medium size $(10-25 \mathrm{~km})$ which were superimposed on the troughs, but no larger craters are present. Subjectively compared to all map units, the surface of the Df unit shows an intermediate crater density. The unit has neither a unique albedo in the clear filter mosaics, nor a unique color in Clementine ratio maps.

Interpretation: Unit Df is interpreted as vestan upper crustal material with troughs formed as a response to the Rheasilvia impact (Buczkowski et al., 2012).

Discussion: The troughs most likely formed by tectonic processes that are associated with the Rheasilvia impact event. Thus the formation age allows integrating unit Df with the Rheasilvia Formation.

\subsubsection{Rheasilvia Formation: Rheasilvia smooth terrain (Rs) and smooth material (s)}

Description: The smooth terrain sub-unit Rs of the Rheasilvia Formation occurs together with the very similar appearing unit $\mathrm{s}$ 
in the very south of the mapping area. The discrimination between the two units was adopted from Krohn et al. (in press): the outside of the Rheasilvia basin starting from its rim is built up by unit Rs. Both terrains are characterized by a smooth, slightly cratered surface showing very small craters of less than $100 \mathrm{~m}$ diameter (Fig. 5C). In contrast to the mostly featureless morphology of unit $\mathrm{s}$, Rs does show large-scale scarps, ridges and grooves. Topographically, unit $s$ is found in higher elevations than Rs. Both units appear relatively bright in FC clear filter images and shows cyan, green and yellowish colors in Clementine color ratios.

Interpretation: The Rs unit largely consists of impact ejecta of Rheasilvia (and perhaps also of older Veneneia ejecta), and formed outside of the Rheasilvia rim, while unit s consists of fine-grained materials deposited by mass movement (Krohn et al., this issue).

\subsubsection{Dark diffuse mantle material (black pattern overlaying other units)}

Description: Deposits of this unit occur in the east of quadrangle Av-7 $\left(124-144^{\circ} \mathrm{E}, 11^{\circ} \mathrm{S}\right.$ to $\left.17^{\circ} \mathrm{N}\right)$, continued to the east in quadrangle Av-8 Marcia, covering an area of $\sim 13,000 \mathrm{~km}^{2}$ in both quadrangles. These deposits seem to be ejecta material originating from and occurring around the $28 \mathrm{~km}$ diameter crater Octavia (located within quadrangle Av-8 Marcia at coordinates $147^{\circ} \mathrm{E} 3^{\circ} \mathrm{S}$; see Williams et al., in press-b). This unit exhibits a diffuse asymmetric
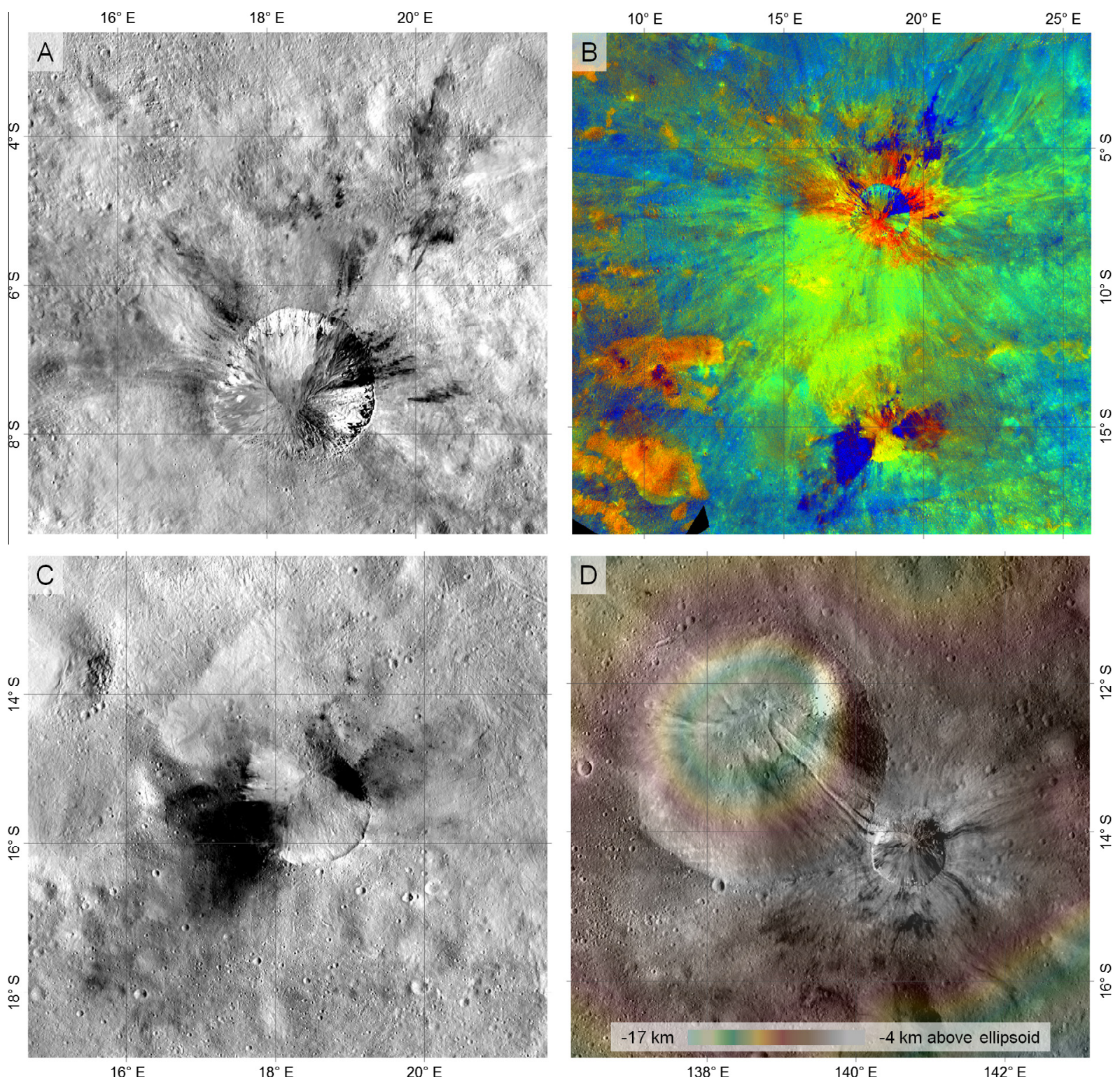

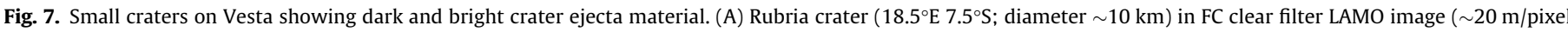

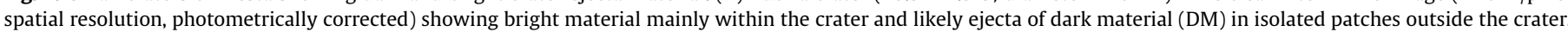

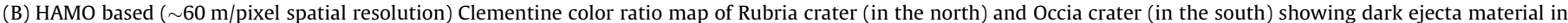

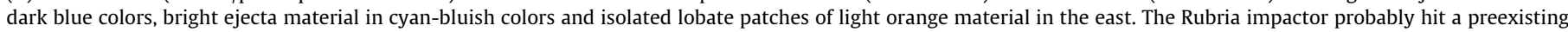

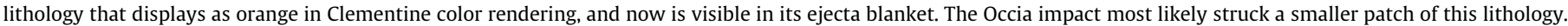

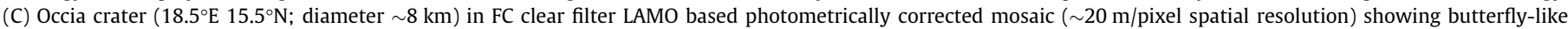

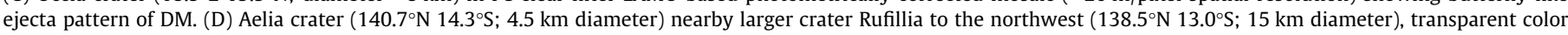

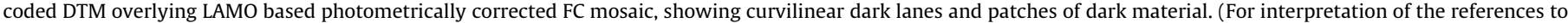
colour in this figure legend, the reader is referred to the web version of this article.) 

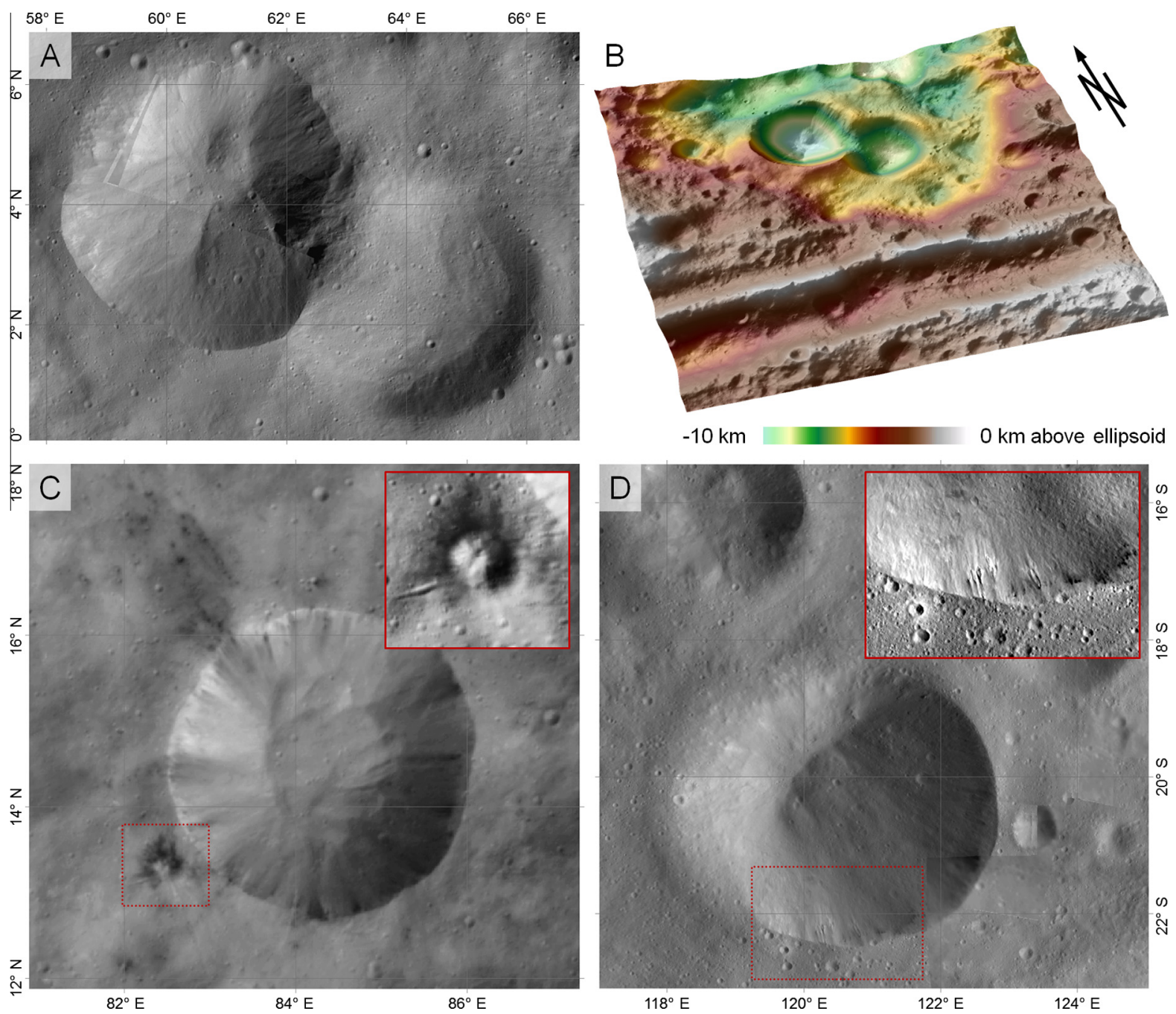

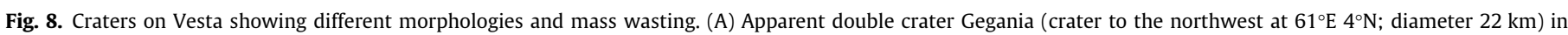

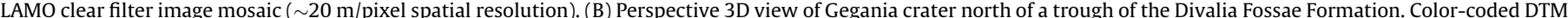

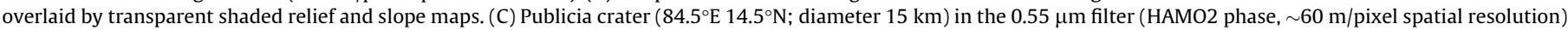

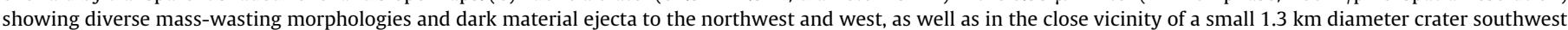

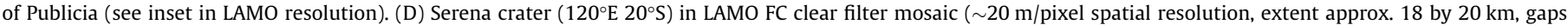

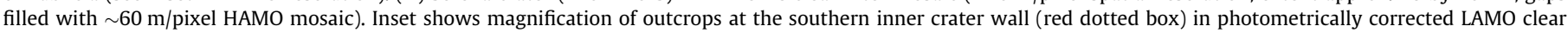
filter image. (For interpretation of the references to colour in this figure legend, the reader is referred to the web version of this article.)

halo (extended to the northwest) with low albedo in the FC clear filter and a remarkable dark orange color in Clementine color ratios (see eastern part of Fig. 2C). Especially in the Clementine color ratio map, the diffuse mantle shows a blending into the surrounding materials, indicating decreasing deposit thickness with increasing distance from Octavia crater.

Interpretation: Ejecta originating from the Octavia impact event.

\subsubsection{Lobate "orange" material (spotted orange pattern overlaying other units)}

Description: In the mapping area of both quadrangles a total of 325 small-sized lobate patches of this unit have been mapped. The lengths of patches range from a few hundreds of meters to approximately $50 \mathrm{~km}$, having areal sizes of $1-579 \mathrm{~km}^{2}$ with a total covered area of $3970 \mathrm{~km}^{2}$ (3.3\% of the mapping area). The orange patches are widespread, but are concentrated in the western part of Av-6 and in the eastern part of Av-7. The unit appears independent of the background on all major map units (ch, Df, Rs, s, t, uc, bc, and dc). Lobate "orange" material shows a remarkably distinct spectral slope in the visual wavelength range compared to ordinary vestan surface material. Thus it can easily be identified in Clementine color ratio images, where its steeper (i.e., more reddish) spectral slope in the visual wavelength range results in light orange colors in the Clementine color ratio map (e.g., in the western part of Fig. 7B). The spectral appearance differs from the dark orange diffuse ejecta material, for example, observed around Octavia (Section 3.5.1). For the differing visible spectral slope, these materials have a slightly higher reflectance in the $0.44 \mu \mathrm{m}$ filter than their surroundings, but they appear nearly indistinguishable in clear filter images, even in the photometrically corrected images. No textural or morphologic changes of the underlying surface can be observed within these areas. In the mapped quadrangles Av-6 and Av-7, orange lobate material occurs mainly in two areas: an area west of the craters Occia and Rubria between $0^{\circ} \mathrm{E} 25^{\circ} \mathrm{S}$ and $25^{\circ} \mathrm{E} 5^{\circ} \mathrm{N}$, including minor patches north of this area, and in an area west of crater Octavia ranging from $70^{\circ} \mathrm{E} 30^{\circ} \mathrm{S}$ to $135^{\circ} \mathrm{E} 20^{\circ} \mathrm{N}$. To the west, occurrences of orange lobate material are continued in quadrangle Av-10 Oppia (Fig. 10; Garry et al., this issue).

Interpretation: Impact ejecta deposits of unique composition, possibly containing impact melt (Le Corre et al., 2013). 

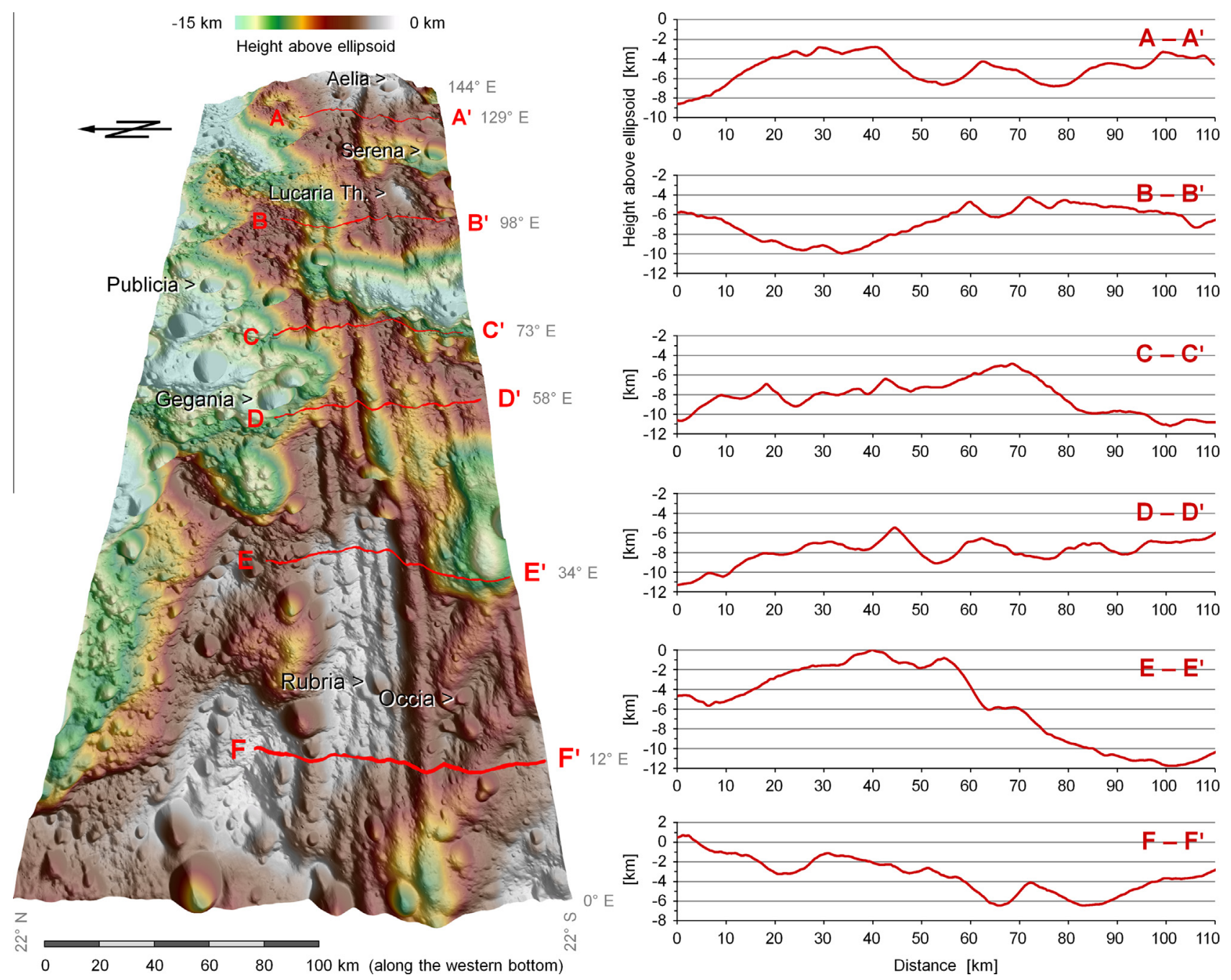

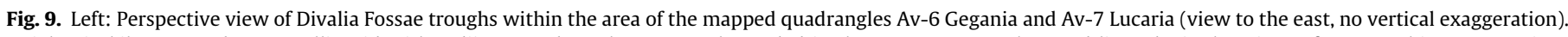

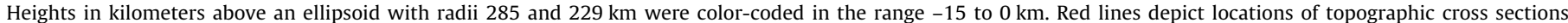

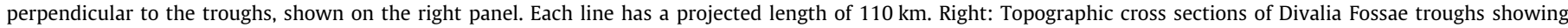

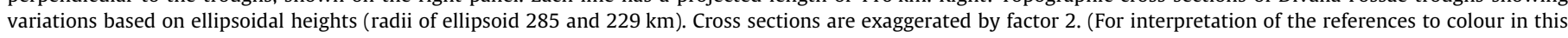
figure legend, the reader is referred to the web version of this article.)

Discussion: On Vesta, the occurrence of light orange material is mainly restricted to the equatorial region between $35^{\circ} \mathrm{S}$ and $30^{\circ} \mathrm{N}$. Le Corre et al. (2013) suggest that their distribution may be related to the Rheasilvia impact basin. Contradictory to this, light orange material is completely absent both within the Rheasilvia basin and within its probable ejecta lobe (described in Section 3.4). More likely, the patches formed in association with several smaller craters, for example the Oppia impact has been proposed as one possible source for light orange material by Garry et al. (this issue). Le Corre et al. (2013) suggest mixtures of ejecta and impact melt containing glassy constituents as the most probable material for light orange material.

\subsubsection{Crater materials: Undifferentiated (uc), bright crater material} (bc), dark crater material (dc), bright crater ray material (bcr), and dark crater ray material (dcr)

Description: Most of the larger craters in our quadrangles display ejecta blankets that have been termed undifferentiated crater material (uc; Fig. 5D), which cover the surroundings of the craters with relatively smooth material ( 25 craters in total). Some also show significant albedo variations and have been termed either as bright (bc; 2 craters) or dark crater material (dc; 2 craters). Other deposits around impact craters form asymmetric radial streaks or patches mantling the underlying material. We mapped these deposits as crater ray material, further differentiated into bright crater ray material (bcr; mapped at crater Rubria) and dark crater ray material (dcr; occurring at 18 craters), depending on their albedo in the clear filter in comparison to the surroundings (see Fig. 7 for examples).

Interpretation: Craters showing high- or low-albedo ejecta are considered to be relatively young impact structures.

Discussion: High albedo ejecta are probable excavates of native vestan crustal material, whereas the low albedo ejecta more likely have an exogenic origin. But the opposite is also conceivable; craters could sample indigenous dark material of a heterogeneous vestan crust, and impacts could deliver brighter materials to Vesta. Reddy et al. (2012b) and Nathues et al. (2014) suggest that dark material (DM) on Vesta originates from a carbonaceous chondritic impactor (possibly of CM2 type) that was deposited earlier on the vestan surface during a low velocity impact event. This exogenous DM was then covered by brecciated vestan material, and then finally re-exposed, excavated and deposited by later impacts (Reddy et al., 2012b). Note, that the definition of DM by Nathues et al. (2014) is more stringent, for their intention was to find 


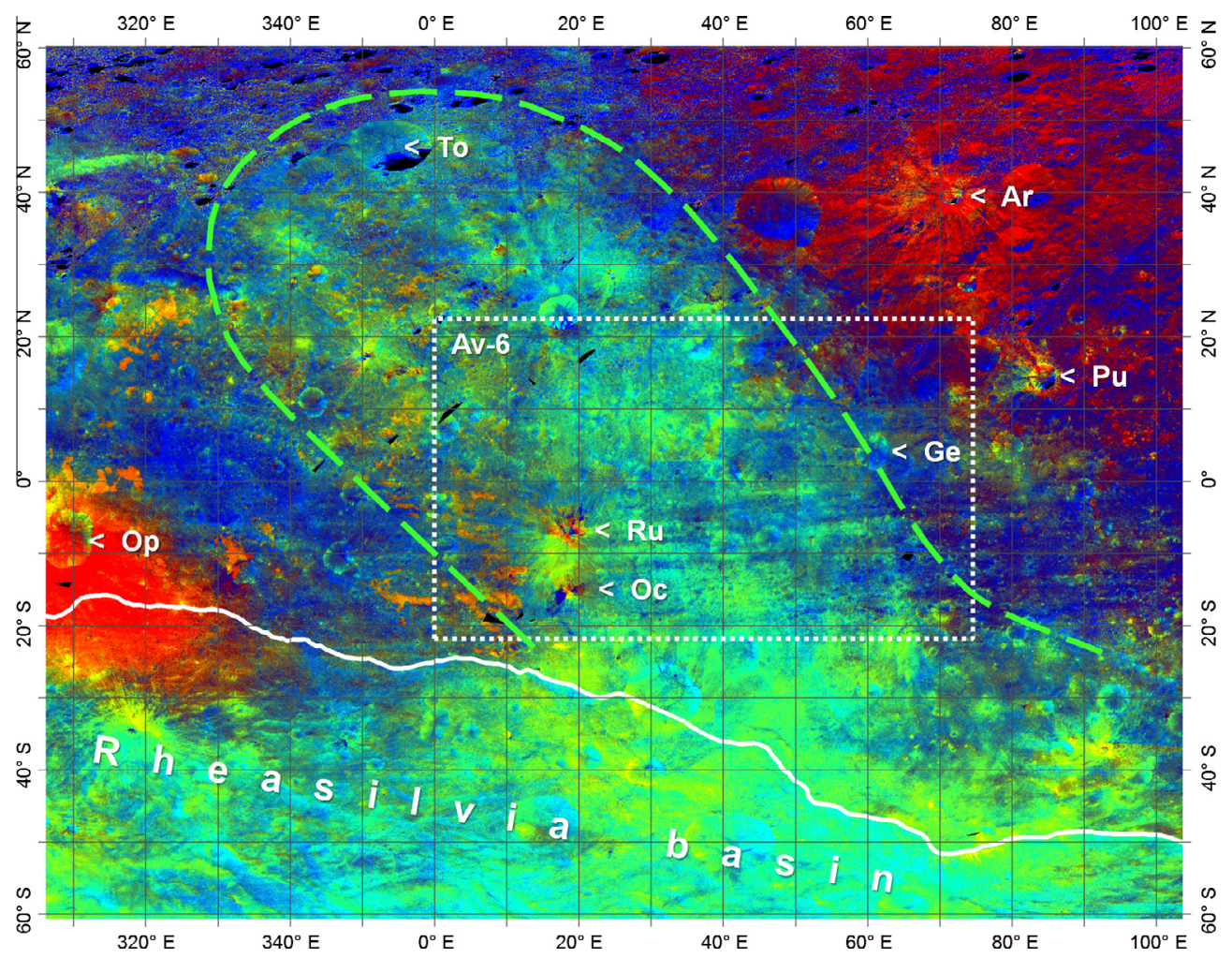

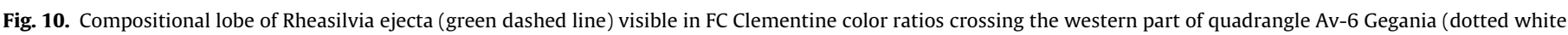

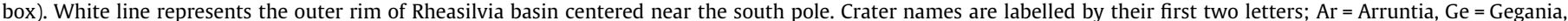

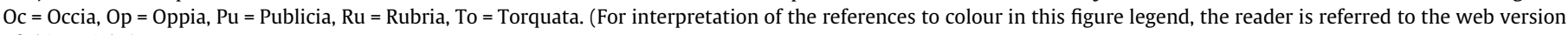
of this article.)

almost pure DM deposits. Using this definition, smaller deposits of DM are found compared with our geologic mapping, located at craters Rubria, Occia, Aelia, within and south of Placidia, and around and east of Publicia. Additionally, five small DM spots are found in the central region of Lucaria Tholus and nine others within the larger dc region mapped at $130^{\circ} \mathrm{E} 20^{\circ} \mathrm{S}$.

\subsubsection{Undifferentiated lobate material ( $u l)$}

Description: The unit ul typically appears as smooth textured deposits, which are lobate or fan-shaped, with cliffs or sharp scarps at their upper margins. Lobate material only occurs within craters on their walls and floors (see Fig. 8 for examples). In total unit ul was mapped at 11 craters within the mapping area.

Interpretation: Deposits of mass-wasting processes down the slopes of crater walls.

Discussion: These lobate mass-wasting materials are probably formed by debris falls, slumping or slope failure on steep slopes within impact craters. The mass wasting might be induced by seismic shaking from nearby impact events.

\subsection{Divalia Fossae troughs}

Divalia Fossae consists of several large-scale E-W-striking flatfloored troughs, with the most prominent named Divalia Fossa. The troughs occur across nearly the entire equatorial area of Vesta between latitudes $25^{\circ} \mathrm{S}$ and $3^{\circ} \mathrm{N}$, being absent only in some parts of Vestalia Terra. In some areas, the Divalia Fossae is built of up to seven parallel running troughs (Fig. 9), with lengths of $90-465 \mathrm{~km}$ (the longest being Divalia Fossa) and widths up to $22 \mathrm{~km}$. They are closely spaced with the intervening high ground thus forming a set of prominent ridges (Yingst et al., 2014). Fig. 9 presents a perspective view of Divalia Fossae in the mapped area including topographic cross sections. The formation is comprised of an elevated terrain with height differences of up to $5.2 \mathrm{~km}$ between adjacent troughs and ridges within the investigated quadrangles (cf. profile E-E' in Fig. 9 between 55 and $64 \mathrm{~km}$ ). Fault displacements of the Divalia Fossa grabens have been investigated by Buczkowski et al. (2012) based on cross sections, who observed at least $5 \mathrm{~km}$ of accommodated vertical displacement (throw).

The Divalia Fossae troughs were likely formed as a result of the Rheasilvia impact (Jaumann et al., 2012). Because the center of Rheasilvia is slightly offset from Vesta's south pole, the Divalia troughs exhibit a curvilinear appearance in the equidistant cylindrical map projection used in this paper (Fig. 9), and are only roughly parallel to the vestan equator. By defining planes through Vesta along the Divalia Fossae troughs, the plane poles cluster at the central mound of the Rheasilvia basin, indicating a causal relationship between the formation mechanism of the troughs and the Rheasilvia impact (Buczkowski et al., 2012; Jaumann et al., 2012).

Fig. 9 shows a few topographic lows, that are more than $10 \mathrm{~km}$ below the reference ellipsoid (in green to blue colors), where the troughs appear much less prominent due to smaller height differences and a less sharp-edged morphological appearance. This suggests that these depressions predate the troughs, or formed about the same time as the troughs itself. An exception is the depression around crater Gegania (cf., Figs. 8B and 9; Section 3.5.5). Here the troughs are completely eroded and/or covered by the ejecta material of Gegania and its nearby crater, indicating that the two craters are younger than the Divalia Fossae troughs. Nevertheless the depression around Gegania is most likely caused by an older impact, and therefore predates Rheasilvia and the troughs. 


\subsection{Rheasilvia ejecta}

The map units Rs and s of the Rheasilvia Formation are present only in the southernmost areas of the Av- 6 and Av-7 quadrangles, with the Divalia Fossae Formation just to the north. However, from a mineralogical point of view, a distinctive $\sim 250 \mathrm{~km}$ wide lobe is visible in the Clementine color ratio map, traversing more than $350 \mathrm{~km}$ through the Av-6 quadrangle (Fig. 10). This lobe continues the Rheasilvia deposits from the south and trending to the northwest across the Divalia Fossae Formation, roughly towards the crater Torquata (within the Av-5 Floronia quadrangle at $354^{\circ} \mathrm{E} 47^{\circ} \mathrm{N}$; labelled with 'T' in Fig. 10). This striking spectral feature appears as a swath of bright material in the FC clear filter images. Reddy et al. (2012a) suggested it to be a thin mantle of material probably ejected during the Rheasilvia impact event. Using the spatially higher resolved LAMO data, the lobe region appears to have a smoother texture than typical vestan terrains outside the Rheasilvia basin, and is crosscut in some parts by numerous small grooves oriented approximately in the north-south direction. In the Clementine color ratio map the lobe shows comparable colors to the Rheasilvia ejecta (ranging from cyan via green to yellowish colors) within and around Vesta's south pole. The bright green/yellow indicates a deeper 1- $\mu \mathrm{m}$ absorption band and is consistent with terrains interpreted to be diogenite-rich howardite, such as in the Rheasilvia basin (Reddy et al., 2012a). This compositionally different material is also evident in the Dawn GRaND data which shows an eastern low-iron lobe extending northward from the Rheasilvia basin (Yamashita et al., 2013). This lobe has a low iron counting rate and possesses almost the same spatial distribution as the region found in FC images. Another comparison between GRaND and FC data is given by Prettyman et al. (2013), where a diogenite rich region with low Percentage of Eucritic Material (POEM) has been found by GRaND in nearly the same area.

\subsection{Prominent large impact craters}

\subsubsection{Crater Octavia}

The $28 \mathrm{~km}$ diameter crater Octavia is located outside the mapping area at $147^{\circ} \mathrm{E} 3^{\circ} \mathrm{S}$ within the quadrangle Av-8 Marcia (Williams et al., in press-b). It is surrounded by a large diffuse ejecta mantle, which covers the eastern part of the Av-7 quadrangle. The diffuse ejecta mantle shows up as dark orange to red colored material in Clementine color ratio maps (see right side of Fig. 2C), due to a steeper spectral slope in the visual wavelength range (Reddy et al., 2012a; Le Corre et al., 2013). Due to the localized occurrence of the increased spectral slope, we interpret it to be a mixture of impactor material and a lithology excavated by the Octavia impactor. The diffuse ejecta material was mapped as Dark diffuse mantle material (see most eastern part of Fig. 4). Similar diffuse material, also appearing dark orange to red in the Clementine color ratio maps, can be identified as ejecta from crater Oppia (Fig. 10) in the Av-10 quadrangle (cf., Garry et al., this issue) and from crater Arruntia (Fig. 10) in the Av-2 Bellicia quadrangle (Ruesch et al., 2014). For a discussion of this material see also Le Corre et al. (2013).

\subsubsection{Crater Rubria}

Rubria is a $\sim 10 \mathrm{~km}$ diameter crater at $18.5^{\circ} \mathrm{E} 7.5^{\circ} \mathrm{S}$, which is superimposed on the equatorial troughs of the Divalia Fossae Formation (Fig. 9). It is located within the likely lane of Rheasilvia ejecta described in Section 3.4 (Fig. 10). Rubria shows a combination of ejecta rays of both bright and dark material (see Fig. 7A). Dark material (DM) occurs in several widespread localities within the crater and in its surroundings (Nathues et al., 2014). Fig. 7B shows the Clementine color ratio map of the Rubria area. The northern half of the ejecta blanket of Rubria shows mainly lobate “orange" material (see also Section 3.2.7) and DM, whereas the southern half is made of higher albedo material, appearing yellow/green in Clementine color ratios, that might be excavated ejecta material with a possibly diogenitic howardite composition similar to Rheasilvia. Bright material crops out at the rim of Rubria and slumps downwards towards the crater center. The DM is located mostly outside of the crater rim in thin long rays, but it also crops out at the rim of the northeastern part of Rubria as isolated blocks scattered within the crater walls. Dark material also forms mass-wasting deposits within the crater. It is likely that all DM streaks, visible in Fig. 7A, are the result of the Rubria impact even though some are isolated and not directly connected to the rim. The longest of these rays is $\sim 16 \mathrm{~km}$ long.

\subsubsection{Crater Occia}

The $\sim 8 \mathrm{~km}$ diameter crater Occia south of Rubria $\left(18.5^{\circ} \mathrm{E}\right.$ $15.5^{\circ} \mathrm{N}$; Figs. 7B, C, and 9) is also located within the lane of Rheasilvia ejecta described in Section 3.4 (Fig. 10). Occia exhibits DM in its broad western ejecta blanket and its smaller eastern ejecta blanket. This DM has an even lower albedo than that associated with Rubria. On the eastern and western sides of Occia DM is also present in the crater walls, where it shows evidence for downslope mass wasting. Occia has a less regular shaped crater and more blurred rim, indicating an age older than the Rubria impact. Moreover, the boundaries between the dark and bright ejecta material at Occia are less distinct and more diffuse than for Rubria, which also implies an older age for Occia. The DM in Occia is mostly confined into triangular-shaped areas, exhibiting two separate lobes of ejecta on the opposite sides of the crater, while the bright material is more evenly distributed.

Both Occia and Rubria exhibit some of the darkest exposures of DM within the mapped area, which indicates that they are almost pure carbonaceous chondrite material of CM type with only minor admixture of vestan HED background material (Reddy et al., 2012b; Nathues et al., 2014). Furthermore, the darkest sites at Occia and Rubria exhibit an absorption feature in the $0.75 \mu \mathrm{m} \mathrm{FC}$ filter, which can be attributed to the mineral serpentine (Nathues et al., 2014).

\subsubsection{Crater Aelia and Rufillia}

Fig. 7D shows the crater Aelia, located on a hill at $140.7^{\circ} \mathrm{E} 14.2^{\circ} \mathrm{S}$ (diameter $4.5 \mathrm{~km}$; see also Fig. 9), which also exhibits dark and bright material within the crater walls and ejecta rays. The ejecta rays were deposited onto the wall of the neighboring larger crater Rufillia ( $138.5^{\circ} \mathrm{E} 13.0^{\circ} \mathrm{S} ; 15 \mathrm{~km}$ diameter) northwest of Aelia, which is much more degraded than Aelia. Dark and bright material crops out from the rim of Aelia and forms mass-wasting deposits towards the center of the crater, and extends in rays outside of the crater rim. The dark and bright material seems to be concentrated in alternating thin, linear deposits less than $1 \mathrm{~km}$ in width. However, investigation of high spatial resolution LAMO imagery indicates that these linear deposits rather correspond to groovelike morphologic surface features, which also cause their curvilinear flow appearance.

\subsubsection{Crater Gegania}

The $22 \mathrm{~km}$ diameter crater Gegania $\left(61^{\circ} \mathrm{E} 4^{\circ} \mathrm{N}\right.$; Figs. 8A, B and 9 and 10) has given its name to the quadrangle Av-6. Gegania is located north of the nearby Divalia Fossae troughs, and has an adjoining unnamed crater of $18 \mathrm{~km}$ diameter to the east (Fig. 8B). This crater, seems to be older than Gegania, as it appears to be overprinted and partly buried by the subsequent impact of Gegania. The surroundings of Gegania show a relatively fresh ejecta blanket, which can be distinguished by its smooth surface texture. Inside Gegania mass-wasting deposits emanate from the northern and southern crater walls, showing lobate morphology (Fig. 8A). 


\subsubsection{Crater Publicia}

Publicia $\left(84.5^{\circ} \mathrm{E} 14.5^{\circ} \mathrm{N}\right.$, Figs. 9 and 10 ; diameter $\left.15 \mathrm{~km}\right)$ is a crater also showing lobate deposits in the form of landslides and mass wasting down the crater walls to the floor (Fig. 8C). Publicia is a bowl shaped crater with a large mound of material in its center, which was formed by downward slumping. The area of the central mound shows a higher density of small craters than the inner walls of Publicia, which therefore indicate younger surface, i.e., suggestive of mass-wasting processes continuing after formation of the central mound. Due to large shadowed areas in the LAMO image, the HAMO2 image mosaic was used in Fig. 8C and shows the DM ejected to the west and northwest, and also a small nearby spot of DM ejected by a $1.3 \mathrm{~km}$ crater southwest of the Publicia rim (see LAMO inset in Fig. 8C).

\subsubsection{Crater Serena}

Crater Serena $\left(120^{\circ} \mathrm{E} 20^{\circ} \mathrm{S}\right)$, depicted in Figs. 8D and 9, has an irregular and asymmetric shape with minimum and maximum diameters of 18 and $20 \mathrm{~km}$. The western rim of Serena is more eroded and smoother than the eastern rim, and appears to be more pristine. Dark and bright materials seem to crop out from irregular thin layers slightly below the southern rim and have slumped down the crater walls (see inset in Fig. 8D). There is a mound of material in the center of Serena and many small craters are scattered within Serena.

\section{Conclusions}

The geologic mapping of quadrangles Av-6 Gegania and Av-7 Lucaria revealed the exceptional influence of the Rheasilvia impact on the mapping area, even though it is situated distant from the Rheasilvia basin itself. Its consequences become apparent both regarding tectonic evidences (via the area's morphology), and mineralogical composition (via spectral surface reflectance).

The Divalia Fossae troughs dominate the morphology of both quadrangles, crossing in a roughly east-west direction along the equator. By analyzing their plane poles, the troughs can be attributed to tectonic deformations in the course of the Rheasilvia impact near the south pole. The DTM shows clear evidence for the troughs, while they remain almost indistinguishable in spectral data.

In the two quadrangles, Rheasilvia ejecta are only present in the very southern areas and typically are composed of diogenite-rich howardites. As can be seen by spectral characteristics, a broad, $350 \mathrm{~km}$ long lobe of similar material cuts through Av-6 quadrangle, and most likely was deposited by the Rheasilvia impact event. This lobe has not been mapped as discrete map unit, since the mapping is based on morphologic rather than spectral criteria. The remaining parts of the mapped region are of primarily howarditic composition, with a general trend of more eucrite-rich compositions towards the eastern border of Av-7.

We investigated surficial ages by relative comparisons of apparent crater densities between the map units. The oldest surface, likely consisting of vestan upper crustal, eucrite-rich material, is found in the north of the two quadrangles, namely the map unit designated as cratered highlands material. To the south, relatively younger formations occur, which are related to the Rheasilvia impact event. The surface age of the unit Divalia Fossae formation is indicated by the troughs which tectonically formed by the Rheasilvia impact. In the very south, the Rheasilvia ejecta display comparable to slightly younger surface ages.

A total of 46 impact craters of medium size (diameters 10$25 \mathrm{~km}$ ) occur within the two quadrangles, with Gegania being the largest crater ( $22 \mathrm{~km}$ diameter) of the whole mapping area. These medium-sized craters likely formed after the Rheasilvia event, and most of them show neither ejecta blankets nor rays. However, some craters exhibit ejecta blankets and/or dark or bright ejecta material in their surroundings and exposures within the crater, indicating younger ages. The youngest deposits are formed by mass-wasting movements down crater slopes, some of them potentially triggered by the most recent impacts.

The mapping of the unusual Lucaria Tholus elevation in the Av7 quadrangle suggests that it is a topographic feature superimposed by low albedo material endogenously delivered by impacts.

\section{Acknowledgments}

The authors would like to thank the Dawn Flight Operations team for a successful Vesta phase, and the MPS, DLR and IDA colleagues who designed, built and tested the Framing Cameras. The Dawn FC project is financially supported by Max Planck Society (MPG, Germany), German Aerospace Center (DLR, Germany), and Jet Propulsion Laboratory (NASA/JPL, USA). The data used in this paper are available from the website http://dawndata. igpp.ucla.edu/.

\section{Appendix A. Supplementary material}

Supplementary geologic maps associated with this article can be found, in the online version, at http://dx.doi.org/10.1016/ j.icarus.2014.06.026.

\section{References}

Anderson, J.A., Sides, S.C., Soltesz, D.L., Sucharski, T.L., Becker, K.J., 2004. Modernization of the integrated software for imagers and spectrometers. Lunar Planet. Sci. 35. Abstract \#2039.

Becker, K.J., Anderson, J.A., Barrett, J.M., Sides, S.C., Titus, T.N., 2012. ISIS support for dawn instruments. Lunar Planet. Sci. 43. Abstract \#2892.

Buczkowski, D.L. et al., 2012. Large-scale troughs on Vesta: A signature of planetary tectonics. Geophys. Res. Lett. 39, L18205.

De Sanctis, M.C. et al., 2011. The VIR spectrometer. Space Sci. Rev. 163, 329-369.

De Sanctis, M.C., Ammannito, E., Capria, M.T., Tosi, F., Capaccioni, F., et al., 2012 Spectroscopic characterization of mineralogy and its diversity across Vesta. Science 336, 697-700.

Garry, W.B. et al., this issue. The Geology of the Oppia Quadrangle of Asteroid (4) Vesta: Determining a Relative Stratigraphy and Establishing a Relative Geologic Timescale through Geologic Mapping.

Gaskell, R.W., 2012. SPC Shape and Topography of Vesta from DAWN Imaging Data. AAS/Division for Planetary Sciences Meeting Abstracts, DPS Meeting 44, \#209.03.

Hapke, B., 2002. Bidirectional reflectance spectroscopy. 5. The coherent backscatter opposition effect and anisotropic scattering. Icarus 157, 523-534.

Jaumann, R., Williams, D.A., Buczkowski, D.L., Yingst, R.A., et al., 2012. Vesta's shape and morphology. Science 336, 687-690.

Keil, K., 2002. Geological history of Asteroid 4 Vesta: The smallest terrestrial planet. In: Bottke, W., Cellino, A., Paolicchi, P., Binzel, R.P. (Eds.), Asteroids III. University of Arizona Press, pp. 573-584, ISBN 0816522812.

Kovacs, G., Sierks, H., Richards, M.L., Gutierrez-Marqués, P., Nathues, A., 2013. Stray light calibration of the Dawn Framing Camera. SPIE Remote Sensing Conference, Proc. SPIE 8889, Sensors, Systems, and Next-Generation Satellites XVII, 888912.

Krohn, K., Jaumann, R., Otto, K., Stephan, K., Wagner, R., Buczkowski, D.L., Garry, B., Williams, D.A., Yingst, R.A., Scully, J., De Sanctis, M.C., Kneissl, T., Schmedemann, N., Kersten, E., Matz, K.-D., Pieters, C.M., Preusker, F., Roatsch, T., Schenk, P. Russell, C.T., Raymond, C.A., 2014. Mass movement on Vesta at steep scarps and crater rims. Icarus, corrected proof published online at http://dx.doi.org/ 10.1016/j.icarus.2014.03.013 (in press).

Le Corre, L., Reddy, V., Schmedemann, N., Becker, K.J., O’Brien, D.P., Yamashita, N. Peplowski, P.N., Prettyman, T.H., Li, J.-Y., Cloutis, E.A., Denevi, B.W., Kneissl, T. Palmer, E., Gaskell, R.W., Nathues, A., Gaffey, M.J., Mittlefehldt, D.W., Garry, W.B., Sierks, H., Russell, C.T., Raymond, C.A., 2013. Olivine or impact melt: Nature of the "Orange" material on Vesta from Dawn. Icarus 226, 1568-1594.

Nathues, A., Hoffmann, M., Cloutis, E.A., Schäfer, M., Reddy, V., Christensen, U., Sierks, H., Thangjam, G.S., Le Corre, L., Mengel, K., Vincent, J.-B., Russell, C.T., Prettyman, T., Schmedemann, N., Kneissl, T., Raymond, C., Gutierrez-Marques, P., Hall, I., Büttner, I., 2014. Detection of serpentine in exogenic carbonaceous chondrite material on Vesta from Dawn FC data. Icarus 239, 222-237.

Pieters, C.M., Staid, M.I., Fischer, E.M., Tompkins, S., He, G., 1994. A sharper view of impact craters from Clementine data. Science 266, 1844-1848.

Prettyman, T.H. et al., 2012. Dawn's gamma ray and neutron detector. Space Sci. Rev. 163, 371-459. 
Prettyman, T.H., Mittlefehldt, D.W., Yamashita, N., Beck, A.W., et al., 2013. Neutron absorption constraints on the composition of 4 Vesta. Meteorit. Planet. Sci. 48 (11), 2211-2236.

Reddy, V., Nathues, A., Le Corre, L., Sierks, H., et al., 2012a. Color and albedo heterogeneity of Vesta from Dawn. Science 336, 700-704.

Reddy, V., Le Corre, L., O’Brien, D.P., Nathues, A., Cloutis, E.A., Durda, D.D., Bottke, W.F., Bhatt, M.U., Nesvorny, D., Buczkowski, D., et al., 2012b. Delivery of dark material to Vesta via carbonaceous chondritic impacts. Icarus 221, 544-559.

Roatsch, T. et al., 2012. High resolution Vesta High Altitude Mapping Orbit (HAMO) Atlas derived from Dawn Framing Camera images. Planet. Space Sci. 73, 283286.

Ruesch, O., Hiesinger, H., Blewett, D.T., Williams, D.A., Buczkowski, D., Scully, J., Yingst, R.A., Roatsch, T., Preusker, F., Jaumann, R., Russell, C.T., Raymond, C.A., 2014. Geologic map of the northern hemisphere of Vesta based on Dawn FC images. Icarus, corrected proof published online at http://dx.doi.org/10.1016/ j.icarus.2014.01.035 (in press).

Russell, C.T., Raymond, C.A., 2011. The Dawn mission to Vesta and Ceres. Space Sci. Rev. 163, 3-23.

Russell, C.T. et al., 2012. Dawn at Vesta: Testing the protoplanetary paradigm. Science 336, 684-686.

Scully, J.E.C., Yin, A., Russell, C.T., Buczkowski, D.L., Williams, D.A., Blewett, D.T., Ruesch, O., Hiesinger, H., Mercer, C. M., Le Corre, L., Garry, W.B., Yingst, R.A. Jaumann, R., Roatsch, T., Preusker, F., Gaskell, R.W., Schröder, S.E., Ammannito,
E., Pieters, C.M., Raymond, C.A., and the Dawn Science Team, 2014 Geomorphology and structural geology of Saturnlia Fossae and adjacent structures in the northern hemisphere of Vesta. Icarus, corrected proof published online at http://dx.doi.org/10.1016/j.icarus.2014.01.013 (in press).

Sierks, H. et al., 2011. The Dawn Framing Camera. Space Sci. Rev. 163 (1-4), 263 327.

Thangjam, G.S. et al., 2013. Lithologic mapping of HED terrains on Vesta using Dawn Framing Camera color data. Meteorit. Planet. Sci. 48 (11), 2199-2210.

Williams, D.A., Yingst, R.A., Garry, W.B., 2014a. Introduction: The geologic mapping of Vesta. Icarus, corrected proof published online at http://dx.doi.org/10.1016/ j.icarus.2014.03.001 (in press-a).

Williams, D.A. Denevi, B.W., Mittlefehldt, D.W., Mest, S.C. Schenk, P.M. Yingst, R.A Buczkowski, D.L., Scully, J.E.C., Garry, W.B., McCord, T.B., Combe, J.-Ph., Jaumann, R., Pieters, C.M., Nathues, A., Le Corre, L., Hoffmann, M., Reddy, V., Roatsch, T. Preusker, F., Marchi, S., Kneissl, T., Neukum, G., Schmedemann, N., Hiesinger, H., De Sanctis, M.C., Ammannito, E., Frigeri, A., Prettyman, T.H., Russell, C.T. Raymond, C.A., and the Dawn Science Team, 2014b. The geology of the marcia quadrangle of asteroid Vesta: Assessing the effects of large, Young Craters Icarus, corrected proof published online at http://dx.doi.org/10.1016/ j.icarus.2014.01.033 (in press-b).

Yamashita, N. et al., 2013. Distribution of iron on Vesta. Meteorit. Planet. Sci., 1-15. Yingst, R.A. et al., 2014. Geologic mapping of Vesta. Planet. Space Sci., http:// dx.doi.org/10.1016/j.pss.2013.12.014. 